\title{
AN UNUSUAL RESULT FOLLOWING TRAUMATIC IRIDO-CYCLITIS
}

BY

\author{
D. J. WOOD \\ CAPE TOWN
}

THIS patient came to me with irido-cyclitis in each eye following operations for cataract. After six months treatment her left eye was operated on-discission-and fair vision was obtained. The right had not improved however.

There was much general redness, but the cornea was fairly bright, so that one could easily see new vessels all over the iris. There was a small coloboma above, but vision was very poor, and there did not seem to be any justification for attempting any operative interference. When I suggested excision the patient agreed at once, glad to be rid of a continually weak, watery, and intermittently painful eye.

Though I had examined her several times with the slit-lamp, I did not think of estimating her corneal thickness, and the interesting pathological condition, found afterwards, was not anticipated.

Over the whole of the back of the cornea was a thick layer of new tissue, thinnest at the edge, but in the centre reaching a thickness two-thirds of that of the cornea.

The deepest parts next to Descemet's membrane are well formed layers of fibrous tissue, the more superficial layers are more granular in texture, contain fewer nuclei, but more particles of uveal pigment, and many blood vessels. There was no layer of endothelium, and when the eye was excised one could see no precipitates, though when I first saw her there were plenty.

The interesting feature is the great transparency of the tissue which did not reveal its existence to myself, or any of my colleagues who saw her. None of us thought of looking at the thickness of the light track through the cornea, otherwise one must have noticed the abnormality.

I have seen a similar condition in the angle of the anterior chamber in a case of leprosy, but there corneal opacity did not permit any vision into the eye, and one could not say whether the new tissue was clear or not.

Now if nature can, under certain conditions, produce clear fibrous tissue, is there not a chance that by imitating these conditions we might get clear scars on the cornea instead of opaque.

One condition would seem to be that the tissue is laid down in the aqueous and friction is absent.

Acting on this idea, I obtained from the depot of Messrs. Zeiss in Johannesburg, a set of their contact glasses with the idea of 
Traumatic IRIDo-Cyclitis

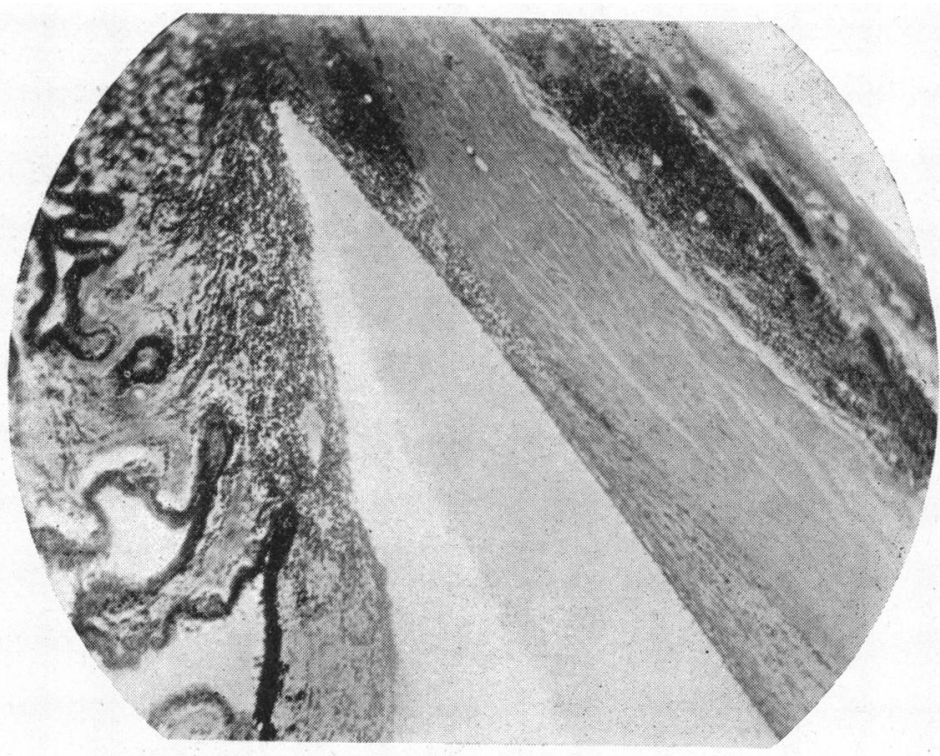

FIG. 1.

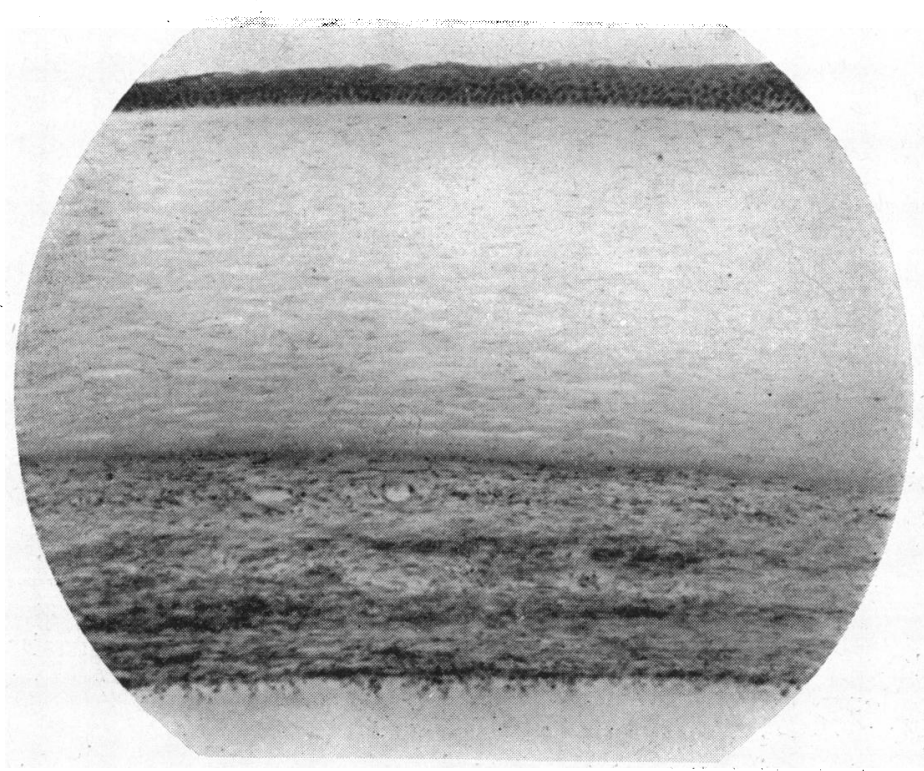

Fig. 2. 
trying them in cases of corneal ulcer. I was, however, unlucky in having only one case during the time I had the contact glasses, and she was unmanageable, and continually got the contact glass out of place. I would like to suggest that some of my colleagues better situated might try the experiment again. After all, one should be in a favourable position to get a cure of an ulcer if one could protect it, and keep it bathed in a sterile natural fluid.

The photographs show (1) the angle of the anterior chamber with a finely granular coagulum, doubtless the source of the

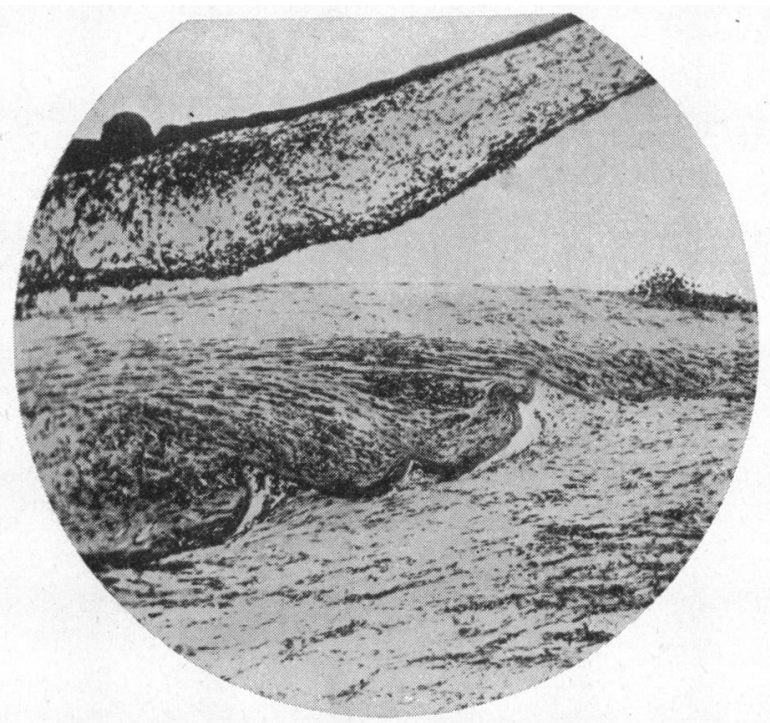

FIG. 3.

fibrinous deposit. At the circumference of the cornea above is the usual mass of lymphocytes found in all cases of chronic iridocyclitis.

(2) The centre of the cornea showing the thick formation of fibrous tissue on the membrane of Descemet. It contains cells, extra-cellular pigment, and blood vessels.

(3) Deposit behind Descemet's membrane in a case of leprosy. The convoluted line of the membrane is visible. The tissue on it is fibrous tissue with many cells. A single precipitate is shown.

Although there were lymphocyte cuffs round the retinal vessels and plenty of well formed plasma cells in the anterior part of the choroid there were no lymphocyte nodules in it, no marked destruction of pigment cells, and no giant cells. In short, it was not a case of sympathetic ophthalmitis. 